\title{
Editorial
}

\section{Orwellian pricing}

Journal of Revenue and Pricing Management (2015) 14, 229-230. doi:10.1057/rpm.2015.29

An Orwellian world has arrived and it's not the government that knows everything about us but Facebook and other data sharing platforms. Everything and everyone you give permission to share your personal data means big data providers know more about you than the CIA. The digital revolution is changing everyday life for many through an immersion culture. There are still many unknowns. What do we do with the information being created and stored all around us? How can it be made to benefit each consumer in his everyday life? What other benefits beyond quenching immediate infothirst can our proliferating connected devices bring us? On one hand, big data has created opportunities for business to deliver personalised products and experiences.

Too create a predictive world in which computer make decisions for you. A future of near-ubiquitous connectivity awaits us. Strings of information promise to emanate from all animate and inanimate things connected via smart and dumb links to the wider digital network. From a pricing perspective, we now inhabit an age in which ever more sophisticated data science holds the promise of perfect price discrimination, that is, individuated transactions in which the customer decides to make a purchase and make it at the highest price she is willing to pay. Retail cultures across the world and beyond are now showing many examples and experiments in the arena of personalisation. Just as product content can be cut and customised to suit the individual shopper so price can be equally well tailored. Price can also be adjusted to reflect contingent human situations. Orwellian pricing of personalisation as arrived.
As customers get used to paying in different ways, in different forms and for different prices for fundamentally the same product they become more sophiscated in the understanding revenue management. Orwellian pricing is the story of the increasing consumer expectations of personalised benefits. Every consumer sector will adopt this approach. Why?

The drivers of this phenomena include: One, the persistence of price sensitivity even in the wealthiest economies where household revenues are growing. Two, the sheer sophistication of predictive analytics machinery and the devotion to big data being expressed within marketing spend. Three, the slowly emerging comfort that millions will soon feel in relation to wearable technology and the focus on individual lifestyle management that is implied. Four, the ever increasing product volumes which are bought online - and not in-store - with conventional, invisible cash. Five, the success of early experiments in retail personalisation - resulting in growingly positive word-of-mouth about the whole idea. Six, the swelling value to corporate profitability of dynamic pricing: optimising price in relation to a customer's location, the channel she is using, the timing of her click (Future Foundation, 2015).

Pay with a Tweet (www.paywithatweet.com/) offers online retailers and content producers the opportunity to maximise the value of social media by allowing customers to pay for a product, video or news article with a tweet instead of using actual money. As the day of the fixed tariff fades back into the last century, so point-of-sale becomes ever more gamefication, with consumers exposed to a different range 
of benefits and rewards depending on which price they choose to make their own. Stayful (stayful.com)has released a mobile app version of its online service that links customers to independent hotels in real time in order to allow them to negotiate the price of their stay.

Basically, pricing has changed and it's not what Orwell (1949) intended in 1984.

\section{REFERENCES}

Future Foundation (2015) My price, http://www.nvisiononline. co.uk, accessed 20 July 2015.

Orwell, G. (1949) Nineteen Eighty Four. London: Penguin Books.

Ian Yeoman

Editor

E-mail: ian.yeoman@vuw.ac.nz 